\title{
Age as a Potential Predictor of Side Effects During Chemoradiotherapy in Primary Cervical Cancer Patients
}

Annica Holmqvist ( $\square$ annika.holmqvist@regionostergotland.se )

Linköping University

Gabriel Lindahl

Linköping University

Rasmus Mikivier

Linköping University

Srinivas Uppungunduri

Linköping University

\section{Research Article}

Keywords: Age, nausea/vomiting, diarrhea, weight loss, chemoradiotherapy, cervical cancer

Posted Date: February 3rd, 2022

DOI: https://doi.org/10.21203/rs.3.rs-1284157/v1

License: (c) (i) This work is licensed under a Creative Commons Attribution 4.0 International License.

Read Full License 


\section{Abstract \\ Background}

Toxicity during chemoradiotherapy (CRT) in cervical cancer patients might limit the chances of receiving an optimal treatment and to be cured. Few studies have shown relationships between side effects and patient's age. Here, the association between age and side effects such as nausea/vomiting, diarrhea and weight loss during CRT was analysed in cervical cancer patients.

\section{Methods}

This study included 93 patients with primary cervical cancer stage IBI to IVA who received CRT from 2013 to 2019. The frequency of symptoms/toxicity grade was analysed by using the Common Terminology Criteria for Adverse Events (CTCAE) version 5.0.

\section{Results}

Patients $\geq 52$ years had a significantly higher frequency of nausea/vomiting and increased grade $\geq 3$ toxicity during CRT compared to younger patients $(p<0.001, p=0.001)$. Toxicity grade $\geq 3$ of nausea/vomiting was associated with increased frequency of weight loss $(p=0.001)$, reduced ADL ( $p=$ $0.001)$ and dose modifications of both radiotherapy (RT) $(p=0.020)$ and chemotherapy (CT) $(p=0.030)$ compared to toxicity grade 2 . The frequency of diarrhea $(p=0.015)$ and weight loss $(p=0.020)$ was higher in older patients compared to younger.

\section{Conclusions}

Older patients have an increased risk of side effects as nausea/vomiting, diarrhea and weight loss. Age could be useful in predicting side effects in primary cervical cancer patients with CRT.

\section{Introduction}

Cervical cancer is one of the leading causes of cancer related death in women, both, in Sweden and globally [1]. It often presents in advanced stages and despite aggressive treatment and recent advances in radiotherapy (RT), the risk of recurrence is still high [2]. Currently, primary chemo-radiotherapy (CRT) is the standard of care in patients with cervical cancer from stage IB2 to IVA. Further, postoperative CRT is recommended in cases of early-stage disease (IB1) with narrow surgical margin or lymph-node metastases [3]. Acute toxic reactions caused by CRT are a common problem and often require dose modifications, which could potentially impair the curative effects of CRT. Previous studies have shown that treatment of cervix cancer patients with intensity modulation radiotherapy (IMRT) significantly 
reduced the level of gastrointestinal $(\mathrm{Gl})$ and hematological toxicity in the pelvic tissue in comparison to conventional RT [4-6].

Today, approximately half of the patients diagnosed with cervical cancer are younger than 50 years. In recent studies, it has been shown that the frequency of acute toxic reaction was distributed equally between older and younger cancer patients [7-9]. A previous large meta-analysis of pelvic cancer patients with conventional RT showed that patients younger than 65 years had a higher frequency of nausea/vomiting compared to older patients [7]. Others found no significant difference in the frequency of nausea/vomiting between cervical cancer patients younger or older than 65 years [10]. A retrospective study involving primary cervical cancer patients treated with CRT showed that older patients had an increased risk of lymphatic and cardiologic toxicity. However, symptoms like nausea/vomiting during CRT, which are common clinical problems for these patients, were not included this study [8].

Diarrhea during CRT is a well know side effect and the frequency in cervical cancer patients varies between $68-96 \%$ [11-14]. A small number of studies have analysed the relationship between age and diarrhea during CRT in cervical cancer patients and found no significant association $[7,8,10]$.

A weight loss of more than $5 \%$ during CRT in cancer patients is known to increase the risk of both malnutrition and morbidity [15]. Few studies have analysed the frequency of weight loss in primary cervical cancer patients during CRT $[16,17]$. Further, the association between age and weight loss has not been studied before.

Adverse effects during CRT are a common problem that could affect the treatment and in consequence, affect the prognosis for these patients. Therefore, early interventions to reduce the acute toxicity may increase the compliance to CRT. The aim of this study was to investigate the frequency and grade of acute side effects as nausea/vomiting, diarrhea and weight loss in relation to age during CRT in primary cervical cancer patients.

\section{Methods}

\section{Patients}

This retrospective cohort study included 93 patients with primary cervical cancer stage IBI to IVA (Fédération Internationale de Gynécologie et d'Obstétrique (FIGO 2009)) who received CRT from October 2013 to April 2019 at the Department of Gynecologic Oncology, University Hospital, Linköping, Sweden. All patients with primary cervical cancer who received either curative or postoperative CRT were asked to participate in the study. All 93 patients had concurrent chemotherapy (CT). The treatment was given according to the national guidelines. Patients with dementia, who were unable to read and speak Swedish or not capable of receiving the standard CRT treatment due to poor performance status and/or comorbidities were not included in the study. The regional ethical committee in Linköping, Sweden approved the study (Reference number: 2018/363-31, 2019/013-33). All patients had signed a written informed consent before the start of the study. 


\section{Data}

Data such as age, stage, grade, time of diagnosis, date of surgery, survival, type of CRT, compliance and side effects during CRT were obtained from the patients' medical records (Table 1). 
Table 1

Clinicopathological factors in relation to age in 93 cervical cancer patients with chemoradiotherapy (CRT).

\begin{tabular}{|c|c|c|c|}
\hline Variables Age & $<52$ years & $\geq 52$ years & p-value \\
\hline$n=93$ & $n=47(\%)$ & $n=46(\%)$ & \\
\hline \multicolumn{4}{|l|}{ Stage } \\
\hline IB1-IB2 & $24(51.1)$ & $7(15.2)$ & 0.003 \\
\hline IIA1-IIB & $16(34.0)$ & $27(58.7)$ & \\
\hline IIIA-IIIB & $6(12.8)$ & $8(17.4)$ & \\
\hline IVA & $1(2.1)$ & $4(8.7)$ & \\
\hline \multicolumn{4}{|l|}{ Histology } \\
\hline Squamous cell carcinoma & $33(70.2)$ & $37(80.4)$ & 0.413 \\
\hline Adenocarcinoma & $12(25.5)$ & $7(15.2)$ & \\
\hline Adenoskvamous carcinoma & 0 & $1(2.2)$ & \\
\hline Others & $2(4.3)$ & $1(2.2)$ & \\
\hline \multicolumn{4}{|l|}{ Type of surgery } \\
\hline No surgery & $31(66.0)$ & $38(82.6)$ & 0.076 \\
\hline $\mathrm{TAH}+\mathrm{SOEB}^{\star}+$ pelvic lymphadenectomy & $14(29.8)$ & $5(10.9)$ & \\
\hline $\mathrm{TAH}+\mathrm{SOEB}^{*}$ & $2(4.2)$ & $3(6.5)$ & \\
\hline \multicolumn{4}{|l|}{ Type of chemoradiotherapy (CRT) } \\
\hline $2 \mathrm{~Gy} \times 25$ pelvis & $10(21.3)$ & $8(17.4)$ & 0.635 \\
\hline 1.8/2Gy x 25 pelvis + cervical brachytherapy (BT) and/or boost & $37(78.7)$ & $38(82.6)$ & \\
\hline \multicolumn{4}{|l|}{ Distrubution of radiotherapy (RT) } \\
\hline Extended-field RT & $7(14.9)$ & $6(13.0)$ & 0.797 \\
\hline No extended-field RT & $40(85.1)$ & $40(87.0)$ & \\
\hline Boost to pelvic/para-aortic lymph-nodes & $16(34.0)$ & $15(32.6)$ & 0.883 \\
\hline No boost to pelvic/para-aortic lymph-nodes & $31(66.0)$ & $31(67.4)$ & \\
\hline \multicolumn{4}{|l|}{ Compliance radiotherapy (RT) } \\
\hline No interruption & $46(97.9)$ & $38(82.6)$ & 0.014 \\
\hline Dose interruption/stopped treatment & $1(2.1)$ & $8(17.4)$ & \\
\hline
\end{tabular}




\begin{tabular}{|llll|}
\hline Variables Age & $<52$ years & $\mathbf{2 5 2}$ years & p-value \\
$\mathbf{n = 9 3}$ & $\mathbf{n = 4 7 ( \% )}$ & $\mathbf{n = 4 6 ( \% )}$ & \\
\hline Compliance chemotherapy (CT) & & & \\
\hline No interruption & $32(68.1)$ & $20(43.5)$ & 0.017 \\
\hline Dose reduction/stopped treatment & $15(31.9)$ & $26(56.5)$ & \\
\hline Hospitalisation & $10(21.3)$ & $25(54.4)$ & 0.001 \\
\hline Yes & $37(78.7)$ & $21(45.6)$ & \\
\hline No & & & \\
\hline Performance status (WHO)** & & & \\
\hline 0 & $43(91.5)$ & $36(78.3)$ & 0.068 \\
\hline 1 & $3(6.4)$ & $10(21.7)$ & \\
\hline 2 & $1(2.1)$ & 0 & \\
\hline Other diseases** & & & \\
\hline No & & $2(4.3)$ & \\
\hline Yes & $45(95.7)$ & $29(63.0)$ & $<0.001$ \\
\hline Diabetes & $2(4.3)$ & $17(37.0)$ & \\
Hypothyreosis & $1(2.1)$ & $9(19.6)$ & \\
Inflammatory bowel disease & $1(2.1)$ & $5(10.9)$ & \\
Cardiovascular disease & 0 & $1(2.2)$ & \\
\hline
\end{tabular}

The primary target volume (PTV), (D98; minimum dose to $98 \%$ volume) and the RT doses to the rectum and bladder (D2cc; minimum dose in Gray (Gy) to $2 \%$ volume) were obtained retrospectively from the radiotherapy treatment planning system (Eclipse ${ }^{\mathrm{TM}}$ Treatment Planning Software $v 16.00$ from Varian Medical Systems). Of 93 patients, RT doses to the rectum and bladder were available for 87 patients. Data was missing for six patients due to incomplete registration at the time point for treatment. Blood tests, patient's weight $(\mathrm{kg})$ and an evaluation of toxicity were repeated weekly during CRT. The acute toxicity during the CRT was evaluated by stratifying for category of side effects and toxicity grade in accordance with the US National Cancer Institute, Common Terminology Criteria for Adverse Events (CTCAE) version $5.0[18,19]$. The CTCAE toxicity for grade 3 of weight loss was set at $\geq 20 \%$, which is, clinically, a very high level of weight loss for these patients. In our study, no patient had such a high level of weight loss (max $11.9 \%$ ) and therefore only grade 1 and 2 toxicity are presented here. Each patients' medical record was studied retrospectively from the start of the CRT to the end of the treatment. The highest grade of toxicity during the CRT treatment according to CTCAE was documented and used for 
further analyses. The frequency/toxicity of side effects were further studied in relation to the age subgroups $<52$ years and $\geq 52$ years. These two subgroups were chosen since the median age of the patients in study was 52 years, which resulted in two sub-groups with equal number of patients. Similar categorization have been used by others [20,21].

\section{Statistics}

The Chi-square $\left(\mathrm{X}^{2}\right)$ test and the Fischer's exact test was used to analyse clinical and pathological factors and to study the differences between the frequency and toxicity grade of the side effects in relation to age. A t-test (independent by groups) were used to calculate the differences in RT doses for PTV and the RT doses to the rectum and bladder related to age. The differences in the overall survival (OS) and progression free survival (PFS) between the two age groups in relation to the side effects were analysed by using the univariate Cox proportional hazard model. Survival curves were calculated according to the Kaplan-Meier method. The software program STATISTICA (version 13.5) was used for the Statistical analyses. The tests were two-sided and a p-value of $p<0.05$ was considered statistically significant.

\section{Results}

\section{Study population}

Ninety-three patients with primary cervical cancer with CRT were included in the study. The majority of the patients $(79.6 \%)$ were in stage IB1 to IIB at the time of diagnosis. Squamous cell carcinoma was present in $75.3 \%$ of the patients and adenocarcinoma in $20.4 \%$ (Table 1). The median age of the patients was 52 years (range 28-79). The mean follow-up for the surviving patients was 46.2 months (range 9-85 months). At the latest follow, 24 (25.8\%) out of 93 patients had local and/or distant recurrence and 19 (20.4\%) had deceased.

\section{Treatment}

The external beam radiotherapy was given with 45-50 Gy in 25 fractions to the pelvis in combination with CT. Of the 93 patients, $19.4 \%$ received pelvic RT alone and $80.6 \%$ pelvic RT + cervical brachytherapy (BT) and/or boost. Thirteen patients (14.0\%) received extended-field RT and 31 patients (33.3\%) received pelvic and or/para-aortic boost to lymph-nodes (Table 1). All treatments were delivered with either IMRT or volumetric modulated arc therapy (VMAT). The concomitant CT consisted of Cisplatin $40 \mathrm{mg} / \mathrm{m}^{2}$ given once a week. The mean number of CT treatments was 4.5 (range 2-6). Fifty-two (55.9\%) of the patients managed all CT treatments without interruption and 35 (37.6\%) had to stop due to side effects. Regarding the RT treatment, eight patients (8.6\%) had dose interruption with prolongation of the time of treatment. One patient (1.1\%) stopped due to side effects (Table 1 ).

\section{Toxicity during chemoradiotherapy}


Of the 93 patients with primary cervical cancer, 76 (81.7\%) had acute side effects as nausea/vomiting and 27 (35.5\%) of these patients had grade $\geq 3$ toxicity (Table 2-3). Patients with grade $\geq 3$ toxicity of nausea/vomiting had a significantly increased frequency of weight loss $(p=0.001)$, reduced $\operatorname{ADL}(p=$ $0.001)$ and dose modifications for both RT/CT $(p=0.020, p=0.030)$ compared to patients with grade 2 toxicity (Table 4). Eighty-one patients (87.1\%) had diarrhea during the CRT out of which 20 patients $(24.7 \%)$ had grade $\geq 3$ toxicity (Table $2-3$ ). Twenty-eight (30.1\%) of 93 patients, had $\geq 5 \%$ weight loss (Table 2).

There was a significant association between frequency and toxicity of nausea/vomiting and diarrhea ( $p=$ $0.025, p<0.0001)$ as well as between frequency of nausea/vomiting and weight loss $(p=0.001)$. No relationship was found between diarrhea and weight loss $(p=0.232)$.

\section{Age in relation to frequency/toxicity of symptoms and survival}

The frequency of side effects and grade of toxicity during CRT was further studied in relation to age in cervical cancer patients. Patient's $\geq 52$ years had a significantly higher frequency of nausea/vomiting during CRT compared to younger patients $(p<0.001$, Table 2, Fig. 1A). In addition, there was an agerelated increase in the grade $\geq 3$ toxicity from $6.4 \%$ in patients $<52$ to $52.2 \%$ in patients $\geq 52$ years $(p=$ 0.001 , Table 3, Fig. 1B). More than half of the 44 patients $\geq 52$ years $(56.8 \%, n=25)$ needed acute hospital admission due to side effects as nausea/vomiting during the CRT compared to $18.8 \%(n=6)$ of the 32 patients $<52$ years ( $p=0.001$, Fig. $1 C)$. A higher frequency and toxicity grade of diarrhea was seen in older patients compared to younger ( $p=0.015, p=0.009$, Table 2-3, Fig. 2A-B). In addition, older patients with diarrhea were admitted for acute hospital care more often than younger patients $(p=0.002$, Fig. $2 C$ ). Patients $\geq 52$ years had a significantly higher frequency of weight loss $\geq 5 \%$ compared to patients $<52$ years $(p=0.020$, Table 2, Fig. 2D). No association was seen between age and toxicity grade of weight loss, most probably due to low number of cases ( $p=0.421$, Table 3, Fig. 2E). Finally, older patients with weight loss $\geq 5 \%$ had an increased risk of acute hospital admission compared to patients $<52$ years $(p=0.028$, Fig. 2F). No significant differences were seen for OS and PFS between patients older or younger than 52 years with respect to nausea/vomiting, diarrhea or weight loss in subgroup analyses $(p>0.05)$. 
Table 2

Number of patients with side effects in relation to age during chemoradiotherapy (CRT) in 93 cervical cancer patients.

\begin{tabular}{|c|c|c|c|c|}
\hline Side effects & $\begin{array}{l}\text { Age } \\
n=93(\%)\end{array}$ & $\begin{array}{l}<52 \text { years } \\
n=47(\%)\end{array}$ & $\begin{array}{l}\geq 52 \text { years } \\
n=46(\%)\end{array}$ & p-value \\
\hline \multicolumn{5}{|c|}{ Nausea/vomiting } \\
\hline Yes & $76(81.7)$ & $32(68.1)$ & $44(95.7)$ & $<0.001$ \\
\hline No & $17(18.3)$ & 15 (31.9) & $2(4.3)$ & \\
\hline \multicolumn{5}{|l|}{ Diarreha } \\
\hline Yes & $81(87.1)$ & $37(78.7)$ & $44(95.7)$ & 0.015 \\
\hline No & $12(12.9)$ & $10(21.3)$ & $2(4.3)$ & \\
\hline \multicolumn{5}{|l|}{ Weight loss } \\
\hline Yes $\geq 5 \%$ & $28(30.1)$ & $9(19.1)$ & $19(41.3)$ & 0.020 \\
\hline No $<5 \%$ & $65(69.9)$ & $38(80.9)$ & $27(58.7)$ & \\
\hline \multicolumn{5}{|l|}{ Limiting ADL } \\
\hline Yes & $20(21.5)$ & $3(6.4)$ & $17(37.0)$ & $<0.001$ \\
\hline No & $73(78.5)$ & $44(93.6)$ & $29(63.0)$ & \\
\hline \multicolumn{5}{|l|}{ Anemia } \\
\hline Yes & $70(75.3)$ & $35(74.5)$ & $35(76.1)$ & 0.856 \\
\hline No & $23(24.7)$ & $12(25.5)$ & $11(23.9)$ & \\
\hline \multicolumn{5}{|c|}{ Trombocytopenia } \\
\hline Yes & $67(62.0)$ & $28(59.6)$ & $39(84.8)$ & 0.007 \\
\hline No & $26(28.0)$ & $19(40.4)$ & $7(15.2)$ & \\
\hline \multicolumn{5}{|l|}{ Leucopenia } \\
\hline Yes & $47(50.5)$ & $22(46.8)$ & $25(54.3)$ & 0.467 \\
\hline No & $46(49.5)$ & $25(53.2)$ & $21(45.7)$ & \\
\hline \multicolumn{5}{|c|}{ Febrile neutropenia } \\
\hline Yes & $16(17.2)$ & $5(10.6)$ & $11(23.9)$ & 0.090 \\
\hline No & $77(82.8)$ & $42(89.4)$ & $35(76.1)$ & \\
\hline Pain & & & & \\
\hline
\end{tabular}




\begin{tabular}{|c|c|c|c|c|}
\hline Side effects & $\begin{array}{l}\text { Age } \\
n=93(\%)\end{array}$ & $\begin{array}{l}<52 \text { years } \\
n=47(\%)\end{array}$ & $\begin{array}{l}\geq 52 \text { years } \\
n=46(\%)\end{array}$ & p-value \\
\hline Yes & $10(10.8)$ & $6(12.8)$ & $4(8.7)$ & 0.526 \\
\hline No & $83(89.2)$ & $41(87.2)$ & $42(91.3)$ & \\
\hline \multicolumn{5}{|c|}{ Urinary symptoms } \\
\hline Yes & $21(22.6)$ & $7(14.9)$ & $14(30.4)$ & 0.073 \\
\hline No & $72(77.4)$ & $40(85.1)$ & $32(69.6)$ & \\
\hline
\end{tabular}


Table 3

The number of patients experiencing various toxicities during chemoradiotherapy (CRT) treatment according to CTCAE (version 5.0) in 93 primary cervical cancer patients.

\begin{tabular}{|llll|}
\hline Toxicity grade & $<52$ years & $\mathbf{2 5 2}$ years & p-value \\
& $\mathbf{n}=\mathbf{4 7}(\%)$ & $\mathbf{n}=\mathbf{4 6}(\%)$ & \\
\hline Nausea/vomiting & & & \\
\hline Grade 2 & $15(31.9)$ & $14(30.4)$ & 0.001 \\
\hline Grade $\geq 3^{*}$ & $3(6.4)$ & $24(52.2)$ & \\
\hline Diarreha & & & \\
\hline Grade 2 & $24(51.1)$ & $25(54.3)$ & 0.009 \\
\hline Grade $\geq 3^{*}$ & $3(6.4)$ & $17(37.0)$ & \\
\hline Weight loss & & & \\
\hline Grade 1 & $10(21.3)$ & $17(37.0)$ & 0.421 \\
\hline Grade $\geq 2 * *$ & 0 & $2(4.3)$ & \\
\hline Limiting ADL & & & \\
\hline Grade 2 & $2(4.3)$ & $1(2.2)$ & 0.046 \\
\hline Grade $\geq 3^{*}$ & $1(2.1)$ & $16(34.8)$ & \\
\hline Anemia & & & \\
\hline Grade 2 & $16(34.0)$ & $12(26.1)$ & 0.624 \\
\hline Grade $\geq 3^{*}$ & $2(4.3)$ & $1(2.2)$ & \\
\hline Trombocytopenia & & & \\
\hline Grade 2 & $9(19.1)$ & $8(17.4)$ & 0.247 \\
\hline Grade $\geq 3^{*}$ & $3(6.4)$ & $7(15.2)$ & \\
\hline Leucopenia & & & \\
\hline Grade 2 & & & \\
\hline Grade $\geq 3^{*}$ & $9(19.1)$ & $14(30.4)$ & \\
\hline Febrile neutropenia & & & \\
\hline Grade 2 & & & \\
\hline Grade $\geq 3^{*}$ & & & \\
\hline Pain & & & \\
\hline
\end{tabular}




\begin{tabular}{|llll|}
\hline Toxicity grade & $\begin{array}{l}<52 \text { years } \\
\mathbf{n = 4 7}(\%)\end{array}$ & $\begin{array}{l}\mathbf{2 5 2} \text { years } \\
\mathbf{n}=\mathbf{4 6}(\%)\end{array}$ & p-value \\
\hline Grade 2 & $1(2.1)$ & $2(4.3)$ & 0.333 \\
\hline Grade $\geq 3^{*}$ & $5(10.6)$ & $2(4.3)$ & \\
\hline Urinary symptoms & & & \\
\hline Grade 2 & $4(8.5)$ & $9(19.6)$ & 0.571 \\
\hline Grade $\geq 3^{*}$ & $1(2.1)$ & $1(2.2)$ & \\
\hline
\end{tabular}

Table 4

Toxicity of nausea/vomiting in relation to the side effects weight loss, ADL, compliance to RT/CT in primary cervical cancer patients.

\begin{tabular}{|lllll|}
\hline Side effects & $\begin{array}{l}\text { Nausea/vomiting } \\
\mathbf{n = 5 6 ( \% )}\end{array}$ & $\begin{array}{l}\text { CTCAE } 2 \\
\mathbf{n = 2 9}(\%)\end{array}$ & $\begin{array}{l}\text { CTCAE } \geq 3 \\
\mathbf{n}=\mathbf{2 7}(\%)\end{array}$ & p-value \\
\hline Weight loss & & & & \\
\hline Yes $\geq 5 \%$ & $27(48.2)$ & $8(27.6)$ & $19(70.4)$ & 0.001 \\
\hline No $<$ 5\% & $29(51.8)$ & $21(72.4)$ & $8(29.6)$ & \\
\hline Limiting ADL & & & & \\
\hline Yes & $17(30.4)$ & $3(10.3)$ & $14(51.9)$ & $<0.001$ \\
\hline No & $39(69.6)$ & $26(89.7)$ & $13(48.1)$ & \\
\hline Compliance RT & & & & \\
\hline Dose modification/stopped treatment & $8(14.3)$ & $1(3.4)$ & $7(25.9)$ & 0.020 \\
\hline No interruption & $48(85.7)$ & $28(96.6)$ & $20(74.1)$ & \\
\hline Compliance CT & & & & \\
\hline Dose modification/stopped treatment & $31(55.4)$ & $12(41.4)$ & $19(70.4)$ & 0.030 \\
\hline No interuption & $25(44.6)$ & $17(58.6)$ & $8(29.6)$ & \\
\hline
\end{tabular}

\section{Side effects related to type of radiotherapy}

Next, the relationship between RT treatment and side effects were analysed in the cervical cancer patients. Patients with pelvic RT + cervical BT and/or boost tended to have a higher frequency of grade $\geq 3$ toxicity of nausea/vomiting compared to patients with pelvic RT alone ( $53.2 \%$ vs $22.2 \%, p=0.089)$. No relationship was seen between weight loss and diarrhea and type of pelvic RT $(p>0.05)$. Neither was there any significant relation between nausea/vomiting, diarrhea or weight loss and extended-field RT or pelvic/para-aortic boost to lymph-nodes $(p>0.05)$. 


\section{Age in relation to clinical variables}

Further, clinical variables were analysed in relation to age in cervical cancer patients with CRT. There was no significant difference between the younger and older patients either for OS or PFS $(p=0.878, p=$ $0.432)$. Patients $\geq 52$ years had an advanced tumour stage $(p=0.003)$, a significantly increased risk of hospital admission $(p=0.001)$, dose modification of RT/CT treatment $(p=0.008, p=0.45)$ and an increased frequency of co-morbidity $(p<0.001)$, (Table 1$)$. No significant associations were found between tumour stage, co-morbidity and the side effects as nausea/vomiting, diarreha and weight loss when analysing the age sub-groups $<\geq 52$ years, separately $(p>0.05)$. There were no differences in the mean RT doses for PTV D98\% or the mean D2cc (Gy) to the rectum and bladder between patients $<52$ and $\geq 52$ years. The mean PTV D98\% for the younger patients compared to the older patients was 85.48 $( \pm$ SD 9.74) Vs.84.24 ( \pm SD 12.60), $(p=0.610)$. The mean D2cc (Gy) to the rectum and bladder for patients $<52$ years compared to patients $\geq 52$ years were 64.0Gy $( \pm$ SD 11.7) Vs. 65.1Gy $( \pm$ SD 11.3), $(p=0.667)$ and 67.1Gy ( \pm SD 14.4) Vs. 70.62Gy ( \pm SD 17.6), $(p=0.314)$.

\section{Discussion}

Adverse effects during CRT are common occurrences in cervical cancer patients and often lead to disruptions of the treatment, which can potentially have a negative effect on the prognosis. Therefore, early detection and mitigation of the adverse effects caused by CRT is important. Previous studies do not provide a clear picture of the relationship between CRT, age and side effects [7-10]. The aim of this study was to analyse common side effects such as nausea/vomiting, weight loss and diarrhea in relation to age during CRT in primary cervical cancer patients.

In the present study, we showed that a majority of the patients $(81.7 \%)$ had symptoms of nausea/vomiting during CRT. We also showed that older patients had a significantly higher frequency of nausea/vomiting during CRT compared to younger patients. Few studies have analysed the relationship between nausea/vomiting, age and pelvic RT/CRT and conflicting results have been presented. Chakraborty et al. (2014) studied primary cervical cancer patients with CRT and found no significant difference between patients younger and older than 65 years with regards to nausea/vomiting [10]. Pignon et al. (1997) showed a reverse relationship compared to ours, with younger patient showing a higher frequency of nausea/vomiting compared to older patients. However, several differences between the two studies including stratification into many age groups, heterogeneous inclusion of many pelvic cancer types and differences in RT treatment could account for these discrepancies [7]. Finally, a metaanalysis on cervical cancer patients with CRT did not include variables as nausea/vomiting at all, which is rather surprising since nausea/vomiting are clinically very common problems for these patients during CRT [8].

Further, we also showed that the toxicity grade of nausea/vomiting during CRT was significantly related to age. In the older patients, grade $\geq 3$ toxicity was present in $52.2 \%$ of the patients compared to $6.4 \%$ in the younger patients. This is a much higher frequency of grade $\geq 3$ toxicity in the older patients compared 
to Chakraborthy et al. (2014) where the grade $\geq 3$ toxicity was present in $14.0 \%$ of the younger and in $8.7 \%$ of the patients older than 65 years [10]. A number of differences between the study by Chakraborty et al. (2014) and the current study could explain these discrepancies. In our study, there were a lower number of patients who interrupted the RT treatment ( $0 \%$ vs $21.7 \%)$ and all patients received concurrent CT ( $100 \%$ vs. $65.2 \%)$. More patients in our study had extended-field RT (13.5\% vs $4.3 \%$ ) and there were also differences in the cut-off value for the age subgroups compared to the other study [10].

We also showed that more than half of the patients in the older group $56.8 \%$ needed hospital admission due to nausea/vomiting during CRT compared to only $18.8 \%$ in the younger group. The patients with toxicity grade $\geq 3$ of vomiting/nausea had a significantly increased frequency of weight loss, reduced ADL and dose modifications of both RT/CT during CRT compared to patients with grade two toxicity. Thus, we can conclude that, patients $\geq 52$ years have an increased risk of side effects as nausea/vomiting, which leads to a higher number of hospital admissions, reduced ADL, increased risk of weight loss and a higher amount of dose modifications of both RT and CT. Therefore, a regular follow up during CRT and early interventions are needed to mitigate these side effects.

Diarrhea during CRT is a well know side effect and the frequency in cervical cancer patients varies from $68.0-96.2 \%$ [11-14]. In line with previous reports, we showed that $87.1 \%$ of our 93 patients had symptoms of diarrhea. In recent studies, no significant relationships have been found between frequency/toxicity of diarrhea and age $[7,8,10]$. Here, we showed that, both, the frequency and toxicity of diarrhea was significantly increased in older patients compared to younger. Further, the incidence of diarrhea lead to more acute hospital admissions in older patients compared to younger.

A weight loss of more than $5 \%$ in cancer patients during CRT is associated with an increased risk of malnutrition and mortality [15]. Few have analyzed the symptoms of weight loss in cervical cancer patients during CRT [16] and no previous report has studied the association between weight loss and age in primary cervical cancer patients with CRT. Here, we showed that the frequency of weight loss was significantly increased in the older patients. Further, a weight loss of more than $5 \%$ leads to a higher risk of acute hospital admission for older patients. We would like to propose that age could be used to predict side effects as diarreha and weight loss in cervical cancer patients with CRT.

Treatment prolongation and unplanned interruption of CRT have a negative impact on OS in cancer patients [22, 23]. One major cause for this is the development of acute side effects during treatment. In our study, we had a higher frequency and more severe grade of side effects, especially nausea/vomiting in the older subgroup of patients, compared to previous studies $[8,10]$. However, despite our findings we could not see any differences in survival between the younger and older patient subgroups. The reduced frequency of treatment interruptions/prolongations could be due to careful monitoring and supportive hospital admissions/medications. This underlines the importance of not only preventing severe side effects but also having a sound supportive strategy, including hospital admission to manage these side effects. As a next step, we plan to initiate an intervention program to study if we can reduce the acute side effects for patients at risk. 
Next, different types of pelvic RT treatments were analysed in relation to nausea/vomiting, diarrhea and weight loss. Here we found a trend towards increased toxicity grade $\geq 3$ of nausea/vomiting in patients with pelvic RT + cervical BT and/or boost compared to patients with pelvic RT alone. No significant relationships were seen between weight loss, diarreah and type of pelvic RT. We propose that pelvic RT + cervical BT and/or boost might contribute to the development of the side effect, nausea/vomiting due to a high RT dose affecting the small intestine located close to the cervix. Future studies, will focus on studying the RT doses in relation to the organs at risk in the pelvic area, especially concerning the treatment dose directed towards the small intestine (bowel bag).

It has been shown that older women are more often diagnosed with an advanced tumor stage compared to younger women [24]. In line with previous reports, the elderly patients in our study had a higher frequency of advanced tumors compared to the younger patients. A more advanced tumor stage might require treatment with higher doses of RT with a corresponding increase in side effects. However, in this study, there were no significant differences in the mean PTV doses given to the pelvis or between the RT doses administered to the rectum and bladder between the age subgroups $<$ or $\geq 52$ years. Neither were there any significant associations between tumor stage and side effects such as nausea/vomiting, diarreha and weight loss in the two age groups. These results make us suggest that the observed differences in frequency/toxicity of the side effects between the two age subgroups is not related to the RT doses. Furthermore, tumor stage does seem to affect risk of having side effects as nausea/vomiting, diarreah and weight loss in subgroup analyses of patients $<$ or $\geq 52$ years.

In this material, in contrast to others, few patients [10] had co-morbidities that could affect the frequency/toxicity of the side effects initiated by the CRT treatment. Also, no significant association was found between co-morbidities and the side effects like nausea/vomiting, diarreha and weight loss when the age sub-groups were analysed separately.

Our study was retrospective and based on a relatively small sample size, which can be a limitation. The study was not randomized and the data was collected from a single cancer care unit. However, the patients came from a relatively large catchment area ( $\sim 1.5$ million inhabitants) and our conclusions are based on real world data, reflecting the normal clinical spectra of patient with different ages and comorbidities.

In conclusion, patient's $\geq 52$ years have an increased risk of side effects as nausea/vomiting, diarrhea and weight loss. Toxicity related to nausea/vomiting was associated with increased risk of weight loss, reduced $A D L$ and dose modifications of CT/RT. We suggest that age can be used to predict side effects in primary cervical cancer patients with CRT. These results might help us in the future to identify the patients who need early interventions.

\section{Declarations}

\section{Ethics approval and consent to participate}


The authors confirm that all methods were carried out in accordance with relevant ethical guidelines and regulations, that all study protocols were approved by the regional ethical committee in Linköping, Sweden (Reference number: 2018/363-31, 2019/013-33). All patients had signed a written informed consent before the start of the study.

\section{Consent for publication}

Not applicable.

\section{Availability of data and materials and Funding}

The datasets used and/or analyzed during the current study available from the corresponding author on reasonable request.

\section{Competing interest}

The authors declare that there are no competing interest.

\section{Funding}

The author declares that there are no funding sources that might generate a conflict of interest.

\section{Authors' contribution}

Annica Holmqvist: Conceptualisation, methodology, formal analysis, investigation, writing - original draft, visualisation, project administration, funding acqusition Gabriel Lindahl: Conceptualisation, validation, writing - review \& editing Rasmus Mikivier: Methodology, validation, formal analysis, writing - review \& editing Srinivas Uppugunduri: Conceptualisation, validation, writing - review \& editing, supervision

\section{Acknowledgements}

This study was supported by grants from the foundation of Oncological Clinical Research in Linköping, the Swedish Cancer Foundation, Swedish Research Council and the Health Research Council in the South-East of Sweden.

\section{References}

1. Arbyn M, Weiderpass E, Bruni L, de Sanjose S, Saraiya M, Ferlay $J$ et al. Estimates of incidence and mortality of cervical cancer in 2018: a worldwide analysis. Lancet Glob Health. 2020;8(2):e191-e203. doi:10.1016/S2214-109X(19)30482-6.

2. Green JA, Kirwan JM, Tierney JF, Symonds P, Fresco L, Collingwood M et al. Survival and recurrence after concomitant chemotherapy and radiotherapy for cancer of the uterine cervix: a systematic review and meta-analysis. Lancet. 2001;358(9284):781-6. doi:10.1016/S0140-6736(01)05965-7. 
3. Rose PG, Bundy BN, Watkins EB, Thigpen JT, Deppe G, Maiman MA et al. Concurrent cisplatin-based radiotherapy and chemotherapy for locally advanced cervical cancer. N Engl J Med. 1999;340(15):1144-53. doi:10.1056/NEJM199904153401502.

4. Gandhi AK, Sharma DN, Rath GK, Julka PK, Subramani V, Sharma S et al. Early clinical outcomes and toxicity of intensity modulated versus conventional pelvic radiation therapy for locally advanced cervix carcinoma: a prospective randomized study. Int J Radiat Oncol Biol Phys. 2013;87(3):542-8. doi:10.1016/j.jijrobp.2013.06.2059.

5. Mell LK, Sirak I, Wei L, Tarnawski R, Mahantshetty U, Yashar CM et al. Bone Marrow-sparing Intensity Modulated Radiation Therapy With Concurrent Cisplatin For Stage IB-IVA Cervical Cancer: An International Multicenter Phase II Clinical Trial (INTERTECC-2). Int J Radiat Oncol Biol Phys. 2017;97(3):536-45. doi:10.1016/j.jjrobp.2016.11.027.

6. Klopp AH, Yeung AR, Deshmukh S, Gil KM, Wenzel L, Westin SN et al. Patient-Reported Toxicity During Pelvic Intensity-Modulated Radiation Therapy: NRG Oncology-RTOG 1203. J Clin Oncol. 2018;36(24):2538-44. doi:10.1200/JC0.2017.77.4273.

7. Pignon T HJ, Bolla M, Poppel $\mathrm{H}$, Bartelink $\mathrm{H}$. Age is not a limiting factor for radical radiotherapy in pelvic malignancies. Raditherapy and Oncology. 1997;42:107-20.

8. Moore KN, Java JJ, Slaughter KN, Rose PG, Lanciano R, DiSilvestro PA et al. Is age a prognostic biomarker for survival among women with locally advanced cervical cancer treated with chemoradiation? An NRG Oncology/Gynecologic Oncology Group ancillary data analysis. Gynecol Oncol. 2016;143(2):294-301. doi:10.1016/j.ygyno.2016.08.317.

9. Goodheart M, Jacobson G, Smith BJ, Zhou L. Chemoradiation for invasive cervical cancer in elderly patients: outcomes and morbidity. Int J Gynecol Cancer. 2008;18(1):95-103. doi:10.1111/j.15251438.2007.00967.x.

10. Chakraborty S, Geetha M, Dessai S, Patil VM. How well do elderly patients with cervical cancer tolerate definitive radiochemotherapy using RapidArc? Results from an institutional audit comparing elderly versus younger patients. Ecancermedicalscience. 2014;8:484. doi:10.3332/ecancer.2014.484.

11. Kirchheiner K, Nout RA, Czajka-Pepl A, Ponocny-Seliger E, Sturdza AE, Dimopoulos JC et al. Health related quality of life and patient reported symptoms before and during definitive radio(chemo)therapy using image-guided adaptive brachytherapy for locally advanced cervical cancer and early recovery - a mono-institutional prospective study. Gynecol Oncol. 2015;136(3):41523. doi:10.1016/j.ygyno.2014.10.031.

12. Kirchheiner K, Potter R, Tanderup K, Lindegaard JC, Haie-Meder C, Petric P et al. Health-Related Quality of Life in Locally Advanced Cervical Cancer Patients After Definitive Chemoradiation Therapy Including Image Guided Adaptive Brachytherapy: An Analysis From the EMBRACE Study. Int J Radiat Oncol Biol Phys. 2016;94(5):1088-98. doi:10.1016/j.jijrobp.2015.12.363.

13. Jensen NBK, Potter R, Kirchheiner K, Fokdal L, Lindegaard JC, Kirisits C et al. Bowel morbidity following radiochemotherapy and image-guided adaptive brachytherapy for cervical cancer: 
Physician- and patient reported outcome from the EMBRACE study. Radiother Oncol. 2018;127(3):431-9. doi:10.1016/j.radonc.2018.05.016.

14. Small W, Jr., Winter K, Levenback C, lyer R, Gaffney D, Asbell S et al. Extended-field irradiation and intracavitary brachytherapy combined with cisplatin chemotherapy for cervical cancer with positive para-aortic or high common iliac lymph nodes: results of ARM 1 of RTOG 0116. Int J Radiat Oncol Biol Phys. 2007;68(4):1081-7. doi:10.1016/j.ijrobp.2007.01.026.

15. Cederholm T, Jensen GL, Correia M, Gonzalez MC, Fukushima R, Higashiguchi T et al. GLIM criteria for the diagnosis of malnutrition - A consensus report from the global clinical nutrition community. $J$ Cachexia Sarcopenia Muscle. 2019;10(1):207-17. doi:10.1002/jcsm.12383.

16. Ohno T, Kato S, Wakatsuki M, Noda SE, Murakami C, Nakamura M et al. Incidence and temporal pattern of anorexia, diarrhea, weight loss, and leukopenia in patients with cervical cancer treated with concurrent radiation therapy and weekly cisplatin: comparison with radiation therapy alone. Gynecol Oncol. 2006;103(1):94-9. doi:10.1016/j.ygyno.2006.01.048.

17. Jou J, Coulter E, Roberts T, Binder P, Saenz C, McHale M et al. Assessment of malnutrition by unintentional weight loss and its implications on oncologic outcomes in patient with locally advanced cervical cancer receiving primary chemoradiation. Gynecol Oncol. 2021;160(3):721-8. doi:10.1016/j.ygyno.2020.12.009.

18. SERVICES USDOHAH. Common Terminology Criteria for Adverse Events (CTCAE) Version 5.02017.

19. Jiang Y, Yuan, L, Wu, Q, Yin, F, Ge, Y. Normal tissue toxicity criteria in radiation therapy. International journal of Radiation Oncology Biology and Physics 2013;87(2):621-2.

20. National Board of Health and Welfare S. Cancer i siffror. 2018:42.

21. Society AC. Key statistics for cervical cancer 2021.

22. Gonzalez Ferreira JA, Jaen Olasolo J, Azinovic I, Jeremic B. Effect of radiotherapy delay in overall treatment time on local control and survival in head and neck cancer: Review of the literature. Rep Pract Oncol Radiother. 2015;20(5):328-39. doi:10.1016/j.rpor.2015.05.010.

23. Freischlag K, Sun Z, Adam MA, Kim J, Palta M, Czito BG et al. Association Between Incomplete Neoadjuvant Radiotherapy and Survival for Patients With Locally Advanced Rectal Cancer. JAMA Surg. 2017;152(6):558-64. doi:10.1001/jamasurg.2017.0010.

24. Sharma C, Deutsch I, Horowitz DP, Hershman DL, Lewin SN, Lu YS et al. Patterns of care and treatment outcomes for elderly women with cervical cancer. Cancer. 2012;118(14):3618-26. doi:10.1002/cncr.26589.

\section{Figures}


Frequency nausea/vomiting

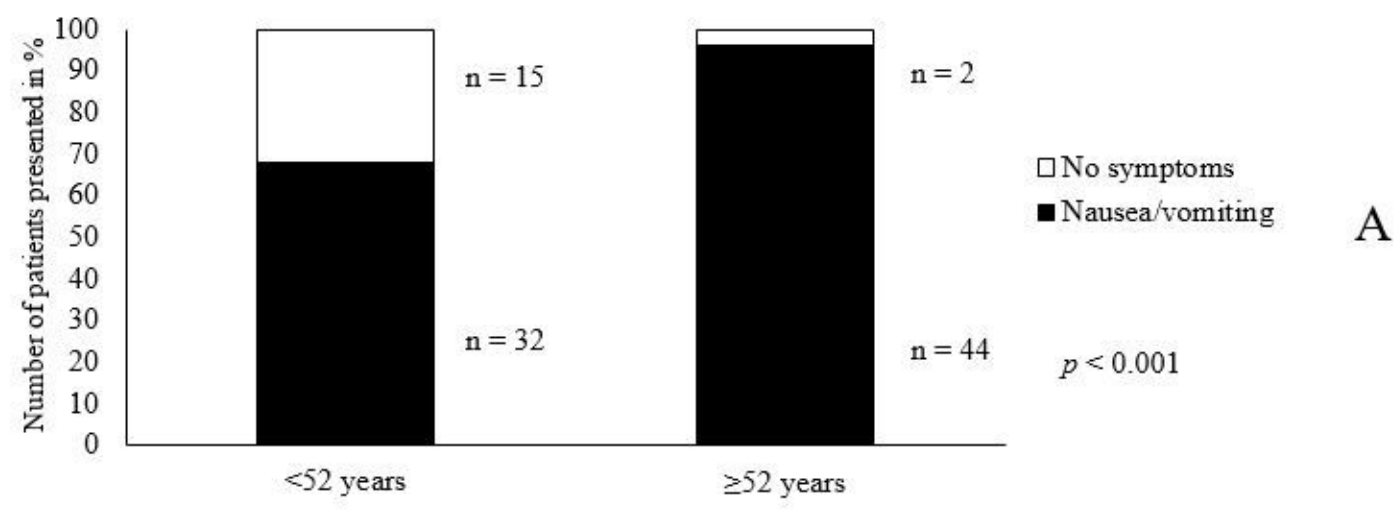

Toxicity nausea/vomiting

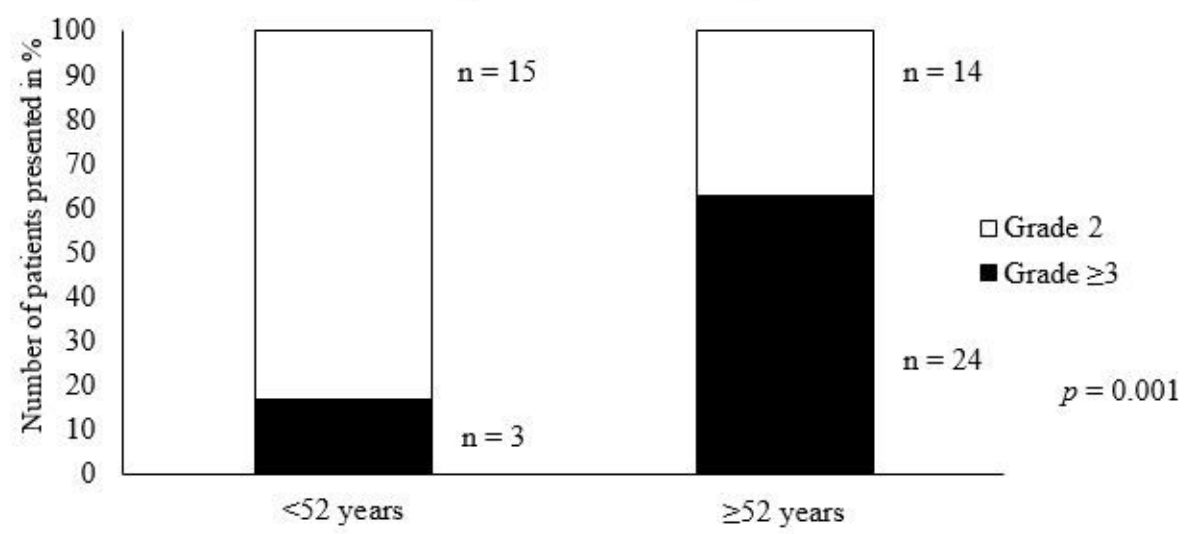

Hospital admission nausea/vomiting

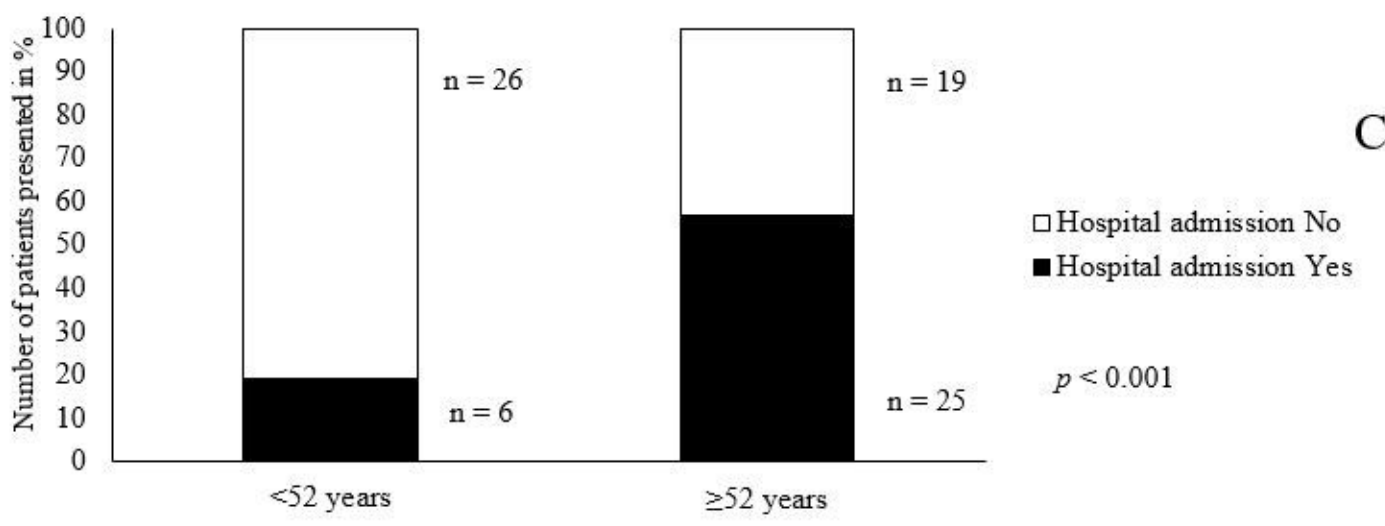

Figure 1

Patients age in relation to frequency of side effects as nausea/vomiting (A), grade of toxicity (B) and number of patients with nausea/vomiting who needed hospital admission (C) in primary cervical cancer patients with CRT. 

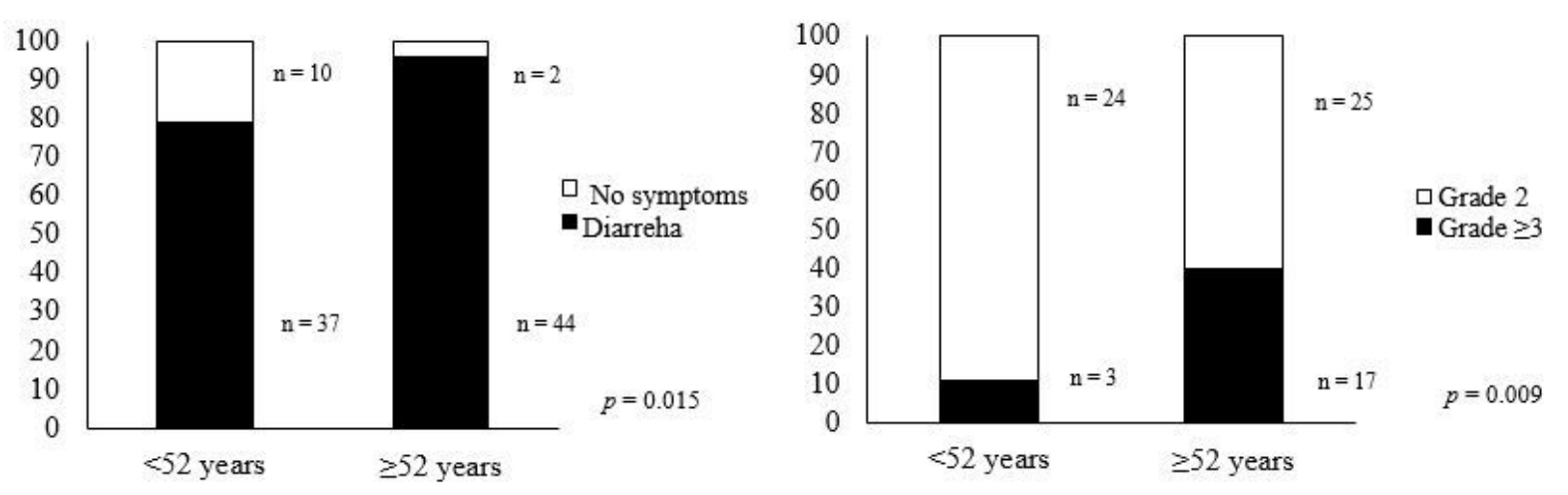

Hospital admission diarreha

C

Frequency weight loss

D
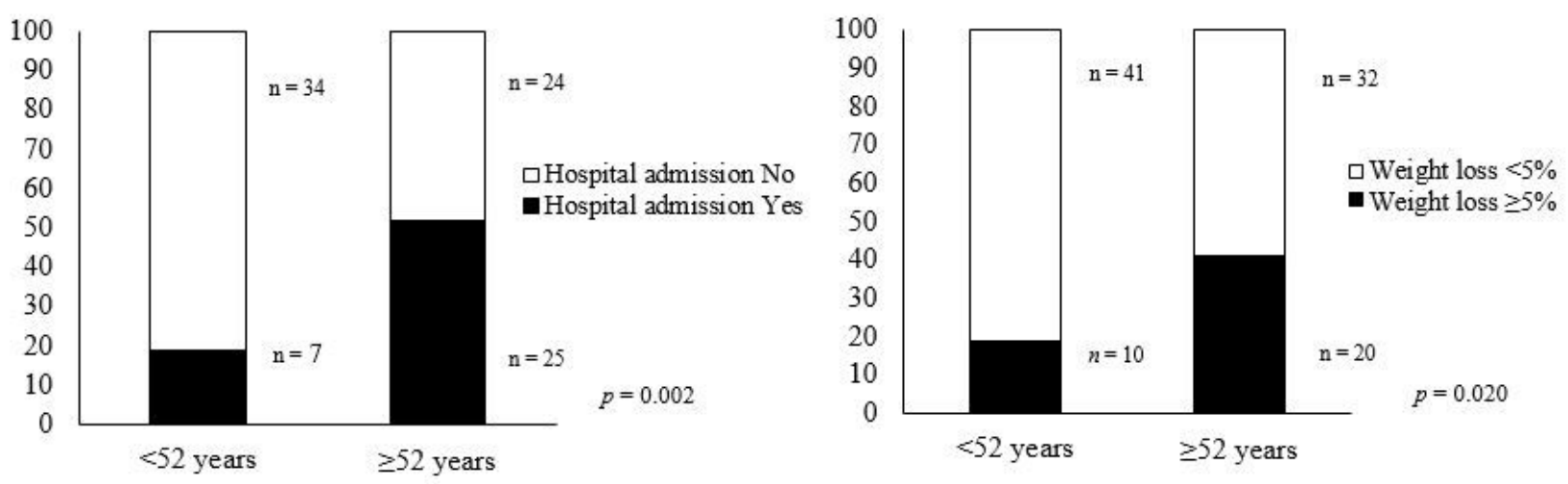

Toxicity weight loss

E

Hospital admission weight loss

F
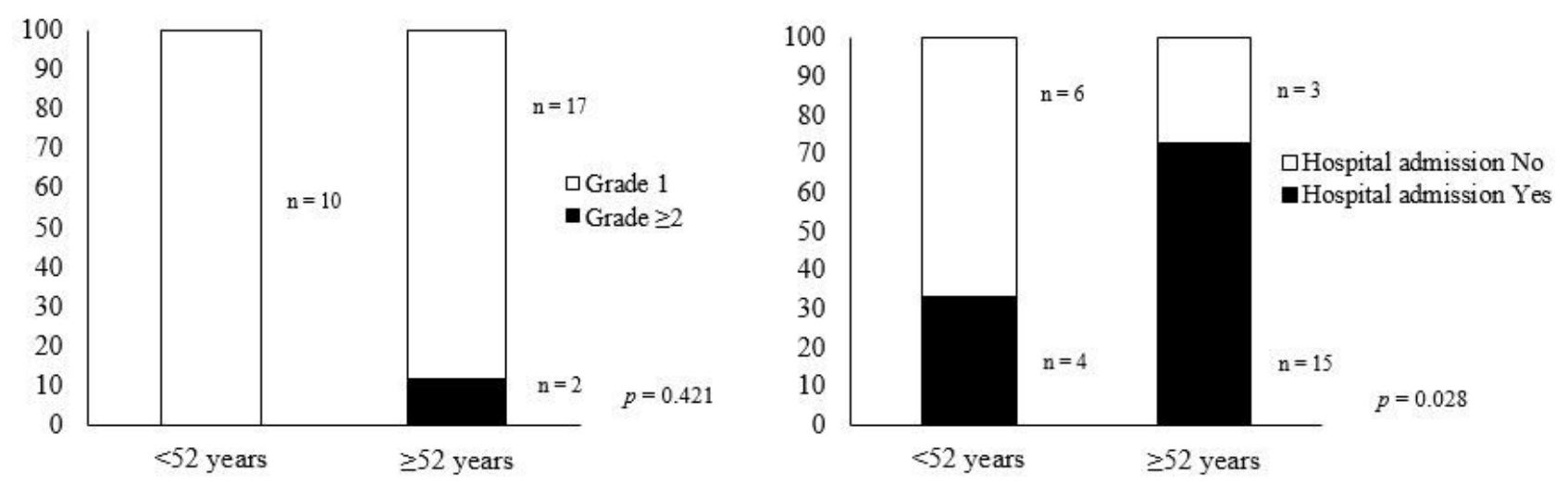

Figure 2

Patient's age in relation to frequency $(A)$ and toxicity grade of diarrhea $(B)$ and number of patients who needed acute hospital admission due to diarrhea (C). Patient's age in relation to frequency (D) and toxicity grade of weight loss (E) and number of patients who needed hospital admission due to weight loss (F) in primary cervical cancer patients with CRT. All figures are presented as number of patients in percent. 